\title{
Gênese do BNDE e os desafios do financiamento de longo prazo para a indústria no Brasil (1952-1954)
}

\author{
Maria Augusta Raspante Sousa*, Fábio Antônio de Campos.
}

\begin{abstract}
Resumo
O objetivo dessa pesquisa foi de analisar o processo de criação de um organismo ligado à concessão de crédito de longo prazo, o Banco Nacional do Desenvolvimento Econômico (BNDE), e se tal acontecimento permitiu criação de um aporte financeiro que fosse capaz de viabilizar a posterior implementação da industrialização pesada no Brasil, durante a segunda metade da década de 50. Para tal foi estudado o plano de governo no qual se encontra sua fundação e as formas de financiamento adotadas ali. $O$ intuito com tal percurso foi de compreender as funções que o Banco assumiu entre os anos de 1952-1954, a estrutura de formação de seu funding e sua relação com o capital estrangeiro e a política externa adotada no Segundo Governo Vargas.
\end{abstract}

\section{Palavras-chave:}

Banco Nacional de Desenvolvimento Econômico (BNDE), Desenvolvimento-Financiamento, Dependência.

\section{Introdução}

A problemática acerca do desenvolvimento foi colocada na pauta de discussão a partir da Grande Depressão que se inaugurou em 1930. A industrialização de alguns países latino-americanos tomou forma dentro desse contexto, naquilo que se convencionou a chamar de desenvolvimentismo. Compreendendo à superação do subdesenvolvimento como algo que transpõe o setor agroexportador em direção à mudança da estrutura produtiva, o Estado tomou as rédeas do processo de desenvolvimento, através do planejamento econômico baseado em estratégias de intervenção estatal.

Entretanto, um dos principais gargalos para a formulação das políticas de cunho desenvolvimentista foi a questão do financiamento. A necessidade de volumosas quantidades de capital de longo prazo para a realização de investimentos nos mais variados setores da economia brasileira esbarrava na capacidade de obtenção e mobilização, interna e externa, desses recursos

Nesse sentido, o objetivo geral desta Iniciação Científica consistiu em estudar o processo de criação do BNDE no Segundo Governo Vargas, ou seja, seus antecedentes de fundação e as implicações que o nascimento dessa instituição exerceu para o projeto de financiamento de longo prazo da economia brasileira no período que se estendeu de 1952 a 1954. E, com isso, analisou-se se foram criadas as bases para sedimentação de um sistema de crédito de longo prazo capaz de viabilizar, durante a segunda metade dos anos 1950, a implantação de uma indústria pesada no Brasil.

\section{Resultados e Discussão}

Foi a figura de Getúlio Vargas que inaugurou um modelo de organização voltado para a constituição de uma indústria de base. Com a Revolução de 1930, o Estado brasileiro passou por modificações em sua burocracia interna, devido a ruptura ocasionada pela desarticulação do padrão de acumulação até então vigente. Assim, o que ocorreu a partir dessa data foi uma nova articulação entre Estado e capital, seja ele nacional ou internacional, capaz de prover a estrutura estatal de capacidade de intervir na economia de forma diferente do que vinha sendo feito até então (VIANNA, 1981).
Em relação ao projeto de governo, Vargas reforçou, ao longo de sua campanha eleitoral, sua percepção acerca dos pontos de estrangulamento para o desenvolvimento brasileiro, apresentando linhas de ação que iam em direção a determinados eixos, como a indústria pesada, agricultura, indústria de base, Estado do bem-estar social e relações exteriores, principalmente no que tange aos empréstimos internacionais.

Entretanto, o financiamento era o principal e recorrente gargalo para a execução do projeto. Com uma estrutura interna composta por bancos comerciais oferecendo crédito, o grosso do aporte para os projetos eram de recursos externos angariados pelas relações geopolíticas estabelecidas por Vargas.

O BNDE veio na esteira dessas relações. Os trabalhos da Comissão Mista Brasil-Estados Unidos deram origem ao Programa de Reaparelhamento Econômico, no qual os recursos estrangeiros captados juntos ao Banco Mundial e Export-Import Bank of United States (Eximbank) para a realização dos projetos seriam intermediados com a criação de um novo banco, o BNDE.

\section{Conclusões}

A partir do que foi brevemente exposto, concluímos que, mesmo com a criação do BNDE, o Brasil não foi capaz de estruturar um sistema de crédito de longo prazo independente, uma vez que os aportes para a constituição do capital do banco ficavam a cargo de organismos internacionais e relações geopolíticas estabelecidas, principalmente com EUA. Com alterações na presidência americana e na importância da América Latina no projeto internacional americano, o financiamento do banco ficava comprometido e, com isso, o projeto de industrialização brasileiro.

\section{Agradecimentos}

Meus sinceros agradecimentos ao meu orientador, Prof. Dr. Fábio Antônio de Campos, pelo suporte institucional e acadêmico, e ao SAE/Unicamp e CNPq, pelo apoio financeiro ao longo do desenvolvimento do projeto.

VIANA, Ana Luiza d'Ávila. O BNDE e a industrialização brasileira 1952-1961. 1981. 421p. Dissertação (mestrado) - Universidade Estadual de Campinas, Instituto de Filosofia e Ciências Humanas, Instituto de Economia, Campinas, SP. 